\title{
OPEN Realizing the full reservoir operation potential during the 2020 Yangtze river floods
}

Hairong Zhang ${ }^{1,2}$, Yanhong Dou ${ }^{3 凶}$, LeiYe ${ }^{3 凶}$, Chi Zhang ${ }^{3}$, Huaming Yao ${ }^{1,2}$, Zhengfeng Bao ${ }^{1,2}$, Zhengyang Tang ${ }^{1,2}$, Yongqiang Wang ${ }^{4}$, Yukai Huang ${ }^{1,2}$, Shuang Zhu ${ }^{5}$, Mengfei Xie ${ }^{6}$, Jiang Wu $u^{4}$, Chao Shi ${ }^{7}$, Yufeng Ren ${ }^{1,2}$, Dongjie Zhang ${ }^{1,2}$, Biqiong Wu ${ }^{1,2}$ \& Yufan Chen ${ }^{1}$

Five severe floods occurred in the Yangtze River Basin, China, between July and August 2020, and the Three Gorges Reservoir (TGR) located in the middle Yangtze River experienced the highest inflow since construction. The world's largest cascade-reservoir group, which counts for 22 cascade reservoirs in the upper Yangtze River, cooperated in real time to control floods. The cooperation prevented evacuation of 600,000 people and extensive inundations of farmlands and aquacultural areas. In addition, no water spillage occurred during the flood control period, resulting in a world-record annual output of the TGR hydropower station. This work describes decision making challenges in the cooperation of super large reservoir groups based on a case-study, controlling the 4th and 5th floods (from Aug-14 to Aug-22), the efforts of technicians, multi-departments, and the state, and reflects on these. To realize the full potential of reservoir operation for the Yangtze River Basin and other basins with large reservoir groups globally, we suggest: (i) improve flood forecast accuracy with a long leading time; (ii) strengthen and further develop ongoing research on reservoir group cooperation; and (iii) improve and implement institutional mechanisms for coordinated operation of large reservoir groups.

Floods are the most frequent natural disaster globally affecting countless lives and property ${ }^{1}$. Reservoirs, one of the most efficient infrastructures in flood $\mathrm{control}^{2}$, were built extensively, such that, cascade-reservoir groups are common in large basins, such as the Nile ${ }^{3}$, the Yangtze River (alias: Changjiang) ${ }^{4}$, the Yellow River ${ }^{5}$, etc. When encountering a severe flood, cascade-order impounding of floods for cascade-reservoir groups can reduce the flood control pressure of a single reservoir and improve the flood control ability of the whole basin ${ }^{6}$. However, each reservoir must manage a balance between flood risk and economic benefit such as power generation and shipping, and benefits gained from different reservoirs vary between each other ${ }^{7,8}$. According to the World Commission on Dams ${ }^{9}$, most large reservoirs worldwide cannot produce benefits the authorities are satisfied with. As a result, the cooperation of cascade-reservoir groups has been extensively considered by hydrologists and decision makers. However, the connection between hydrologists and decision makers is relatively weak, although there are many studies on reservoir cooperation ${ }^{10-13}$, little feedback and reflection has emerged from users. In this work, we describe challenges, achievements and reflections of the cooperation practice of the world's largest cascade-reservoir group in the upper Yangtze River when facing a flood larger than that with a 100 -year recurrence interval.

The Yangtze River, the third-longest river in the world, plays an paramount role in the economy, energy, and ecology of China ${ }^{14-17}$; it has a basin area of $1.8 \times 10^{6} \mathrm{~km}^{2}$ that serves a population of nearly 50 million people, generates $40 \%$ of the China's Gross Domestic Product (GDP), and outputs $30 \%$ of China's grain. The Yangtze River Basin is shown in Fig. 1a, where the distribution of population density is developed by Socioeconomic Data and Applications Center ${ }^{18}$. Reservoir groups on the upper Yangtze River are vital for flood control in the middle and lower regions ${ }^{19,20}$. The largest cooperation system of reservoirs in the world is constructed in the upper Yangtze River Basin, as shown in Fig. 1b, which counts for 22 cascade reservoirs with a total flood control

\footnotetext{
${ }^{1}$ China Yangtze Power Co., Ltd., Yichang 443133, China. ${ }^{2}$ Hubei Key Laboratory of Intelligent Yangtze and Hydroelectric Science, Yichang 443133, China. ${ }^{3}$ School of Hydraulic Engineering, Dalian University of Technology, Dalian 116024, China. ${ }^{4}$ Changjiang River Scientiffic Research Institute, Wuhan 430074, China. ${ }^{5}$ School of Geography and Information Engineering, China University of Geosciences, Wuhan 430074, China. ${ }^{6}$ Kunming Power Exchange Center Co., Ltd., Kunming 650011, China. ${ }^{7}$ Yunnan Power Grid Co., Ltd., Kunming 650011, China. ${ }^{\circledR}$ email: dou.yhong@gmail.com; yelei@dlut.edu.cn
} 


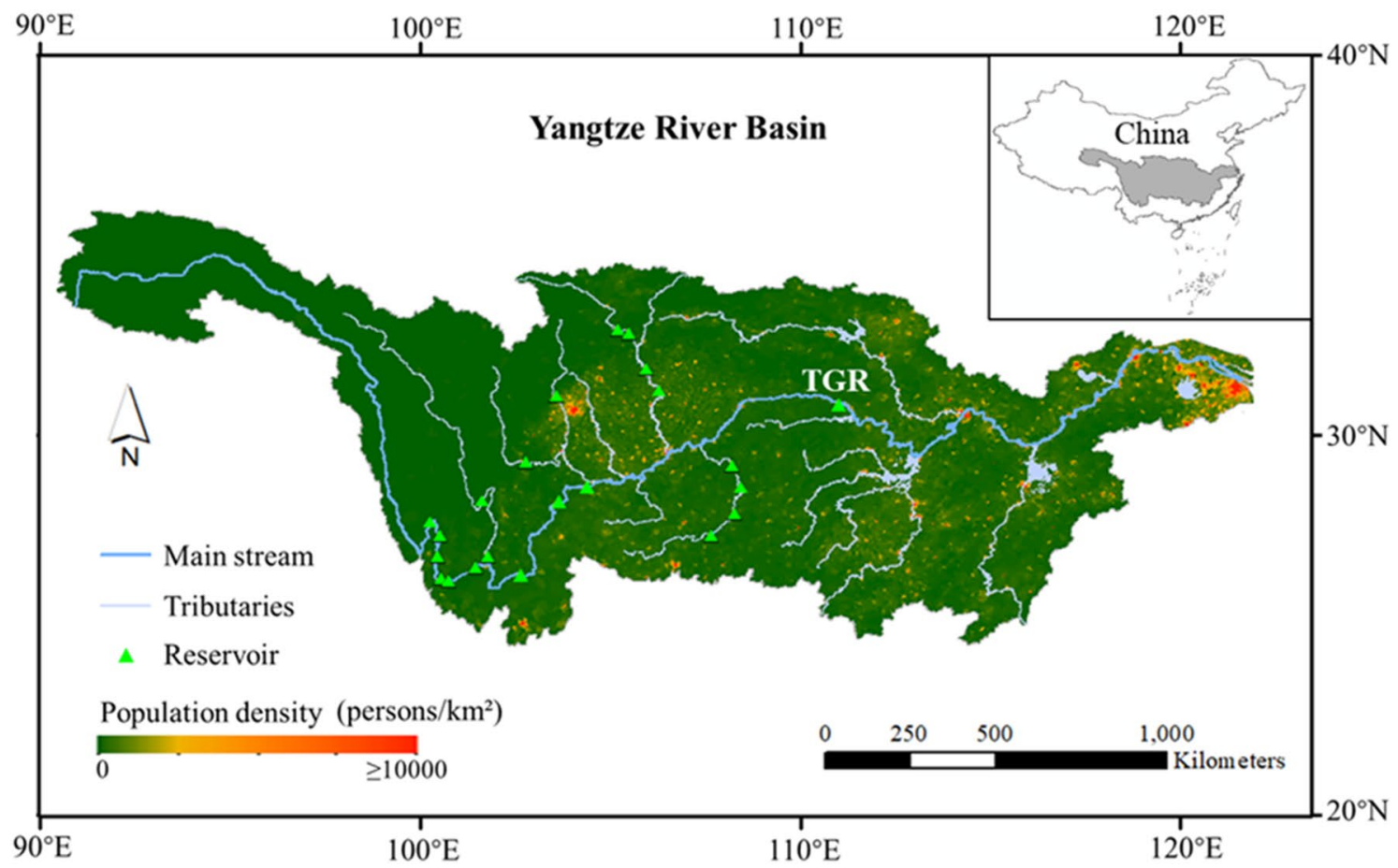

(a)

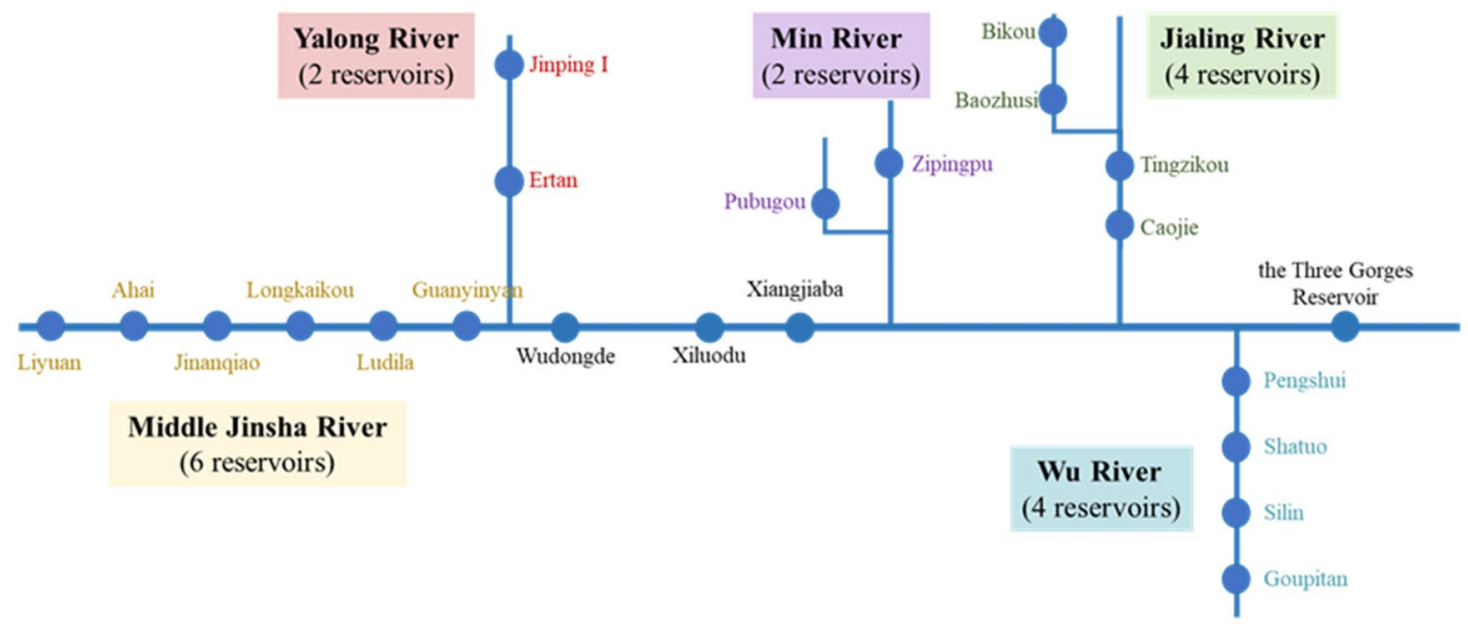

(b)

Figure 1. (a) The geographical location, streams, reservoirs and population density of Yangzte River Basin generated by ArcGIS 10.2. (b) Sketch map of 22 reservoirs on the upper Yangtze River included in the joint operation until 2020, where the circles represent reservoirs.

capacity of $38.7 \times 10^{9} \mathrm{~m}^{321}$. The system takes the Three Gorges Reservoir (TGR; largest installed capacity in the world) as the core reservoir, the cascade reservoirs in the lower Jinsha River, including Wudongde (7th), Xiluodu (4th), and Xiangjiaba (11th), as the main reservoirs, and the cascade reservoir groups in the middle Jinsha River (six reservoirs), Yalong River (two reservoirs), Min River (two reservoirs), Jialing River (four reservoirs), and Wu River (four reservoirs) as the coordinating reservoirs.

\section{Challenges}

Severe floods of Yangtze river. Rainfall distribution is grossly inhomogeneous in both spatial and temporal aspects in the Yangtze River Basin, benefiting from its location in the subtropical monsoon climate zone on the east coast of Eurasia ${ }^{22,23}$. As a result, floods occur frequently in the Yangtze River Basin and are usually characterized by a strong sudden occurrence, significant areal extent, and massive loss of lives and property ${ }^{24,25}$. 


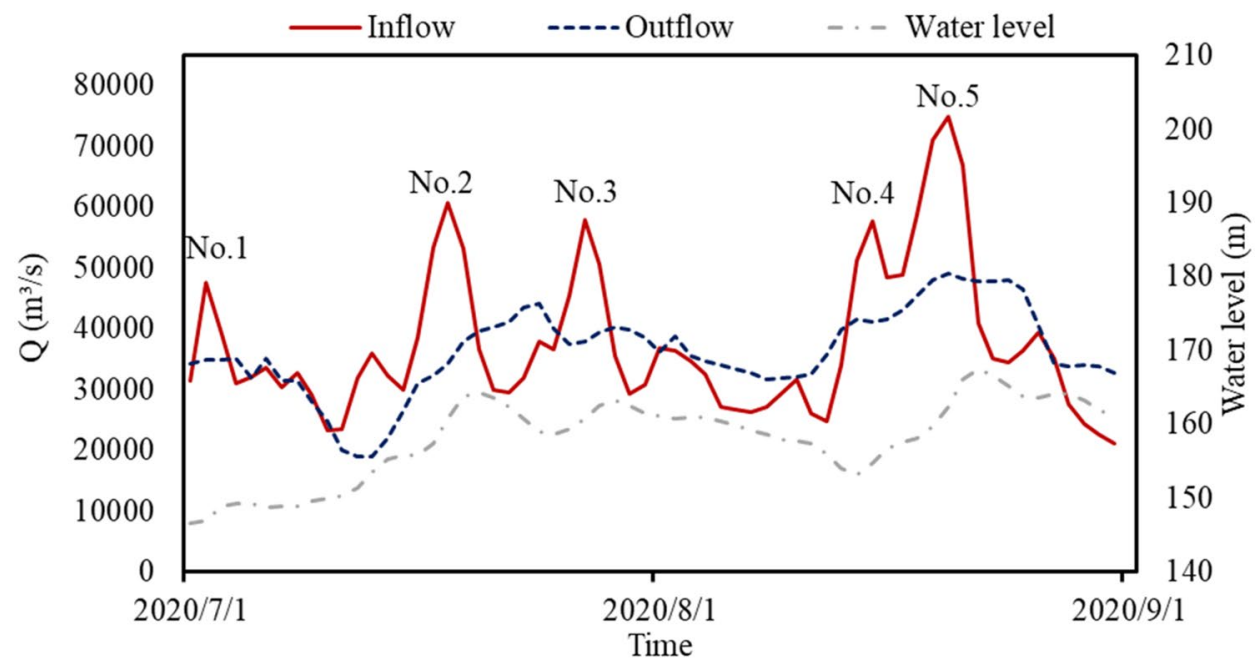

Figure 2. Outflow, inflow, and water level of TGR during 2020 flood season.

In 2020, five severe floods occurred between July and August along the Yangtze River as shown in Fig. 2. The TGR, located in the middle Yangtze River, experienced the highest inflow of $74,600 \mathrm{~m}^{3} / \mathrm{s}$ since its construction. Among the five numbered floods, 4th and 5th floods (from Aug-14 to Aug-22) were caused by two continuous rainfalls characterized by long duration, high intensity, and overlapping rainfall fields which covered most of the upper Yangtze River. During the rainstorm, the 5-day accumulated rainfall exceeded $400 \mathrm{~mm}$, meaning that half of the average annual rainfall fell in just five days. As a result, flood peaks of the upper Yangtze River tributaries would encounter before entering the TGR and a flood larger than that with a 100-year recurrence interval would be formed without reservoir operation.

Complex operating decision of super large reservoir groups. Cooperation of reservoirs in the mainstream and tributaries. According to the joint operation scheme, when a severe flood occurs, the TGR and the 21 upstream reservoirs will coordinate with each other to control the flood. This means that the upstream reservoirs would not only perform their own flood control tasks, but also reserve part of their flood control capacity, known as reserved flood control capacity, to cooperate with the TGR to mitigate flooding in the middle and lower regions of the Yangtze River. The mainstream flood may be comprised of two or even more floods in the tributaries owing to the numerous tributaries and their frequent flood encounters in the Yangtze River ${ }^{26}$. Considering the complicated composition of mainstream floods, various cooperation schemes should be used for the reservoirs on the mainstream and tributaries. Additionally, the distance between each reservoir group is significant as shown in Fig. 1a, which increases the inherent uncertainty of flood routing and rainstorm displacement direction forecasting. Therefore, the real-time joint operation of the super large reservoir groups faces the problem of how to determine the utilization order of the reserved flood control capacity, as well as how much to use and maintain.

Impact on stable power supply. The cascade hydropower stations on the upper Yangtze River are the key power sources of China ${ }^{27}$. The theoretical and exploitable hydropower resources in the Yangtze River Basin are $2.68 \times 10^{9} \mathrm{~kW}$ and $2.35 \times 10^{9} \mathrm{~kW}$, respectively, out of which the upper Yangtze River accounts for more than $90 \%$. Considering the Xiluodu-Xiangjiaba-Three Gorges cascade stations as an example, these three stations are responsible for power supply to nine of the most economically developed provinces and cities in China, including Guangdong, Jiangsu, Zhejiang, and Shanghai ${ }^{28}$. However, when cooperating with the downstream or mainstream reservoirs, the upstream or tributary reservoirs must reduce discharge to release the reserved flood control capacity, leading to a decrease in the output of the hydropower stations and making it difficult to generate stable power as specified in the original generation schedule ${ }^{29-31}$. With respect to the status of the cascade hydropower stations on the upper Yangtze River, erratic hydropower supply affects other power sources in the power grid like dominoes, particularly by decreasing the output during the peak summer months. Therefore, the second problem that the real-time joint operation of super large reservoir groups faces is how to adjust the generation schedule.

Impact on safe operation. During a severe flood, the increasing inflow and flexible discharge of reservoirs quickly change the water levels of both upstream and downstream dams, impacting the safe operation of water conservation projects ${ }^{32}$ and shipping transportation. Taking Xiangjiaba reservoir as an example, if the daily variation in the water level exceeds $4 \mathrm{~m}$, it leads to reservoir bank instability ${ }^{33}$, and if the water level variation is too large in the downstream dam, shipping safety is affected ${ }^{8}$. Therefore, precise control of water level variation is necessary, particularly at night, adding additional uncertainties owing to fewer staff. 


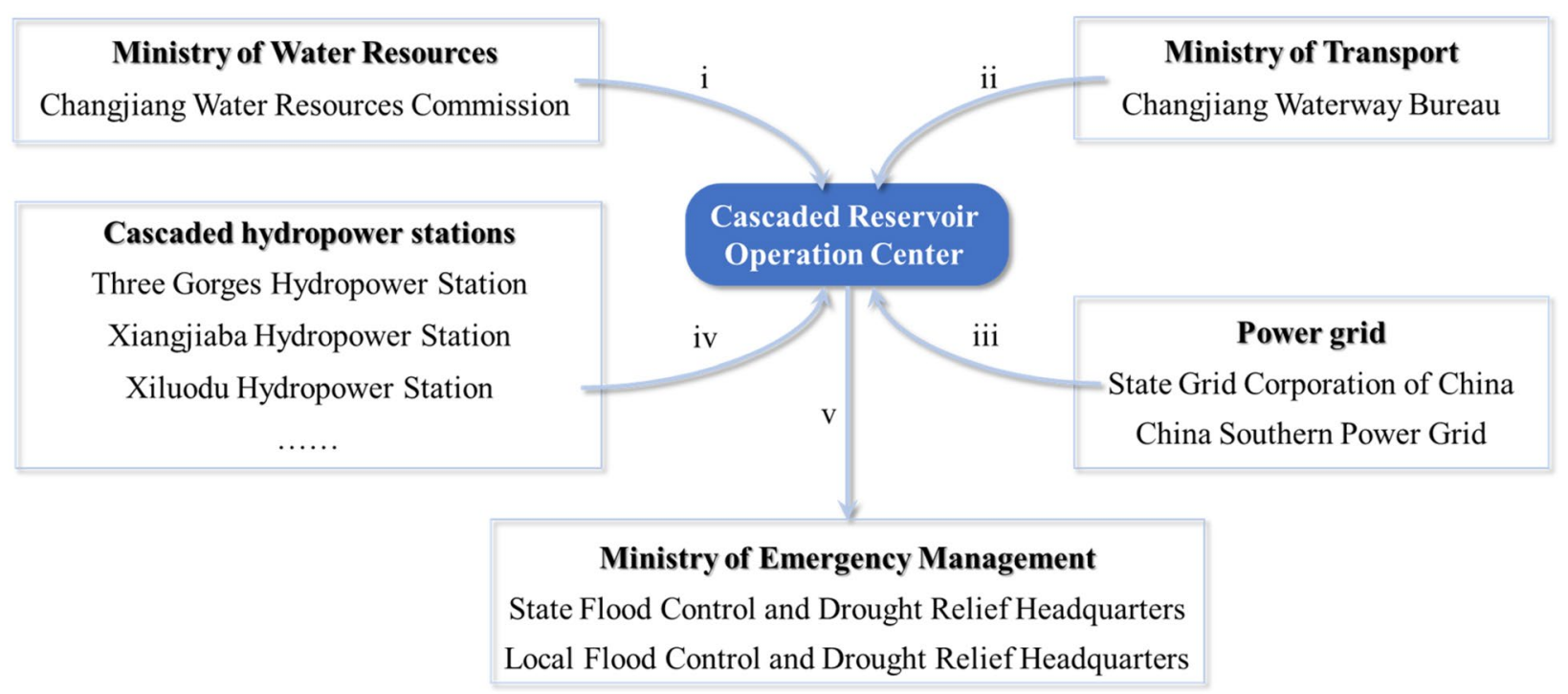

Figure 3. The relationship between six types of water-related departments, where i to iv indicate the objectives and/or requirements of each corresponding type of department for reservoir cooperation, and $v$ indicates the submission of the cooperation scheme ensemble from Cascaded Reservoir Operation Center (CROC) to Flood Control and Drought Relief Headquarters (FCDRH) considering the above objectives and requirements. The final cooperation scheme is determined through multi-department consultation under the leadership of FCDRH.

Coordination of multiple departments. Each reservoir included in the upper Yangtze River cooperation system is responsible for multiple simultaneous missions, such as flood control, power generation, and shipping ${ }^{7,8}$, etc. The operation of reservoirs affects the competition-relation benefits of multiple departments ${ }^{34}$. For example, when facing a flood, the objective of Changjiang Water Resources Commission (CWRC) of the Ministry of Water Resources ( $\mathrm{i}$ in the Fig. 3) is mitigating the threat of flood to the protection objectives in the basin, such as populated localities, factories and farmlands. For this purpose, impounding and/or discharging of reservoirs will cause frequent changes of water level and flow, which affects shipping and power generation significantly. Both the Changjiang Waterway Bureau (CWB) of the Ministry of Transport and power grid corporations hope to reduce the duration of such abnormal operation as much as possible (ii and iii in the Fig. 3). Additionally, it is necessary to consider maintenance schedules and upper limits of transmission for each hydropower station (iv in the Fig. 3). Therefore, one problem reservoir cooperation decision making faces, is how to manage and balance the objectives and requirements of multi-departments.

\section{Achievements of cascade-reservoir cooperation}

Flood control. To prevent the 1st, 2nd, and 3rd floods of the Yangtze River in $2020,20.5 \times 10^{9} \mathrm{~m}^{3}$ of the flood control capacity of the 22 joint-operation reservoirs was used, accounting for $53 \%$ of the total flood control capacity. On this basis, to prevent the 4 th and 5 th floods, the cascade reservoir groups cooperated on a large scale again and held up $19.0 \times 10^{9} \mathrm{~m}^{3}$ of flood volume. There is $8.2 \times 10^{9} \mathrm{~m}^{3}$ of flood volume held up by the 21 reservoirs upstream of the TGR, as shown in Fig. 4, which prevented flood peak encounters of the Jinsha River (Xiangjiaba Station), Minjiang River (Gaochang Station), and Jialing River (Beibei Station). As a result, before the flood enters the TGR (Cuntan Station), the flood peak with a 90 -year recurrence interval $\left(87,500 \mathrm{~m}^{3} / \mathrm{s}\right)$ was reduced to 20 years $\left(74,600 \mathrm{~m}^{3} / \mathrm{s}\right)$, the flood volume with a 130 -year recurrence interval was reduced to 40 years $\left(36.00 \times 10^{9} \mathrm{~m}^{3}\right)$, and the peak river stage was reduced by $3 \mathrm{~m}$. In this manner, flood control pressure at the tail of the TGR was significantly mitigated. The other $10.8 \times 10^{9} \mathrm{~m}^{3}$ of flood volume was held up by the TGR, which reduced the flood with a 50-year recurrence interval $\left(40.00 \times 10^{9} \mathrm{~m}^{3}\right)$ to an ordinary flood and avoided the utilization of the Jingiiang Flood Diversion Area. The above flood control cooperation prevented significant direct property loss in the middle Yangtze River, such as the evacuation of 600,000 people and inundation of $330 \mathrm{~km}^{3}$ of farmlands and more than $70 \mathrm{~km}^{3}$ of aquaculture areas.

Hydropower generation. In response to flood control, power grid companies adjusted the hydropower generation schedules of relevant reservoirs efficiently and scientifically to ensure stable power supply, efficient use of water resources, and greater power generation. Taking the operation of the Xiangjiaba Reservoir during the 4th and 5th flood as an example, the Xiangjiaba Reservoir had to reduce the discharge and hold the flood in order to cooperate with the TGR, resulting in decreased flow through the turbine and the plummeting power generation. The State Grid quickly adjusted the power generation schedule, that is, permitted the output of the Xiangjiaba hydropower station to be reduced to $2.2 \times 10^{6} \mathrm{~kW}$ at 17:00 on Aug. 17, and subsequently, the output was increased to the rated power at 9:00 a.m. on Aug. 19. During the entire process, no water spillage occurred. As a result, the Xiluodu-Xiangjiaba cascade hydropower stations and the single station of the TGR generated 


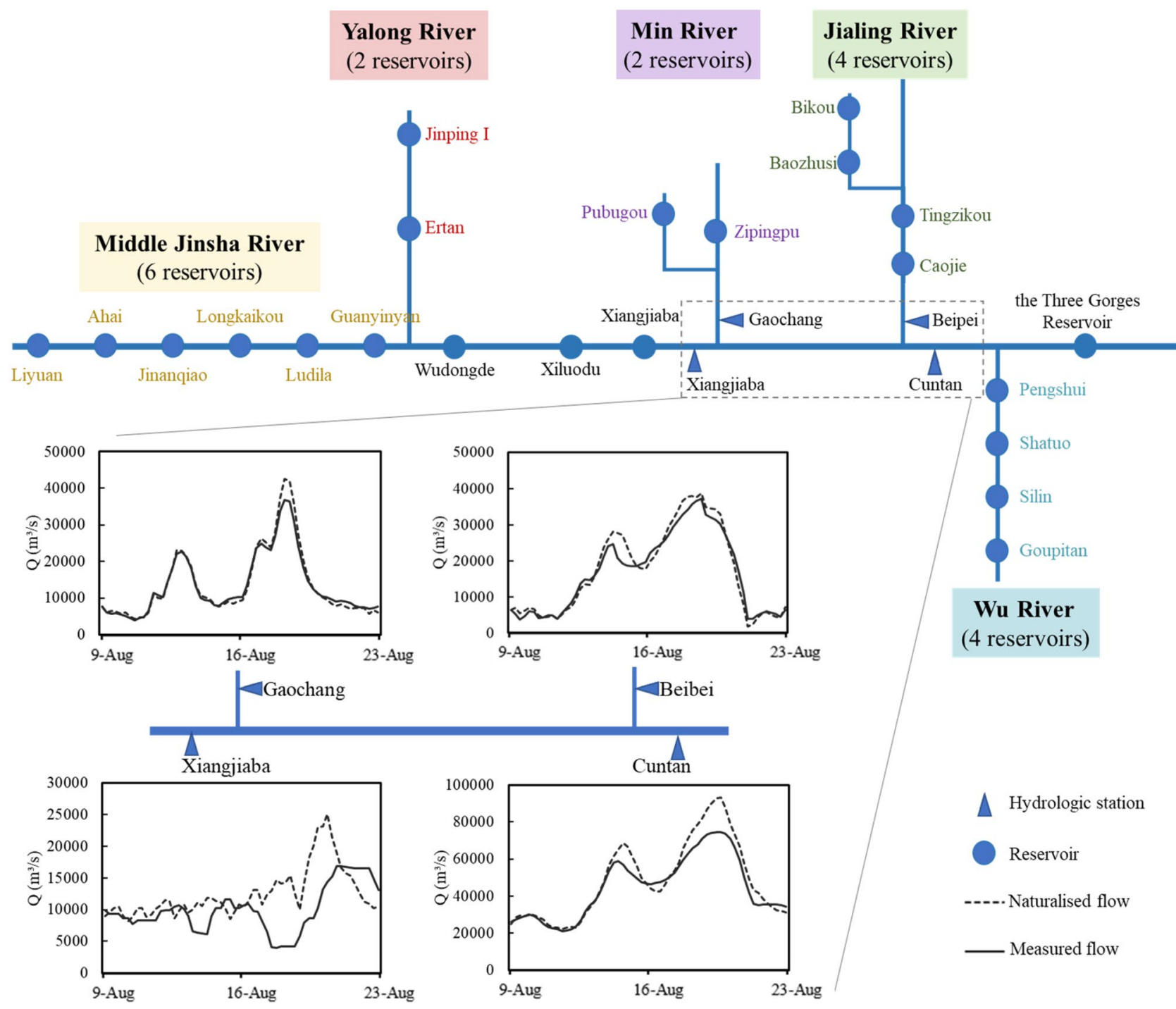

Figure 4. The triangles represent the hydrological stations; and naturalized and measured flows of major hydrological stations in the upper Yangtze River during 4th and 5th floods, where the naturalized flow of the stations on the Jinsha River (Xiangjiaba), Min River (Gaochang), Jialing River (Beibei), and upstream of the TGR (Cuntan) is obtained using the Intelligent Changjiang Decision Support System (ICDSS) according to the actual operational data of upstream reservoirs and considering the flood travel time and water balance.

electricity outputs of $3.20 \times 10^{10} \mathrm{kWh}$ and $1.67 \times 10^{10} \mathrm{kWh}$, respectively in August 2020 , which are $49 \%$ and $42 \%$, respectively more than the 10 -year average in the same period. In addition, the TGR hydropower station generated electricity output of $1.12 \times 10^{11} \mathrm{kWh}$ in 2020 , hitting a world record for annual output of a single hydropower station ${ }^{35}$.

Safe operation. The water level variations of both the upstream and downstream dams met the corresponding regulation during the flood control cooperation owing to the benefit derived from the forecast of precipitation and hydrology and the simulation of hydrodynamics and reservoir operation. The daily water level variation of the Xiluodu and Xiangjiaba reservoirs were $4.95 \mathrm{~m}$ ( $5 \mathrm{~m}$ in regulation) and $3.73 \mathrm{~m}$ (4 m in regulation) respectively, which is the largest since their construction. From July to September 2020, more than 4500 ships and 15 million tons of cargo successfully passed through the waterway in an orderly manner.

\section{Reflections}

Real-time cooperation was adopted for cascade reservoir groups for controlling floods in 2020, realizing the full reservoir operation potential. During the real-time cooperation, conventional operation schedules and regulations are always not applicable. Below are three key reflections from the reservoir operation during the 2020 Yangtze River flood. 


\begin{tabular}{|l|l|l|l|l|l|l|l|}
\hline \multirow{2}{*}{ No } & Measured & Peak flow $\left(\mathbf{m}^{3} / \mathbf{s}\right)$ & Peak time & Leading time & Peak flow $\left(\mathbf{m}^{3} / \mathbf{s}\right)$ & Peak time & Evaluation \\
\hline \multirow{2}{*}{4} & \multirow{2}{*}{62,000} & \multirow{2}{*}{ Aug-15 } & 5 day & 50,000 & Aug-16 & $-19.35 \%$ & 1 day \\
\cline { 4 - 8 } & & 1 day & 62,000 & Aug-15 & 0 & 0 \\
\hline \multirow{2}{*}{5} & \multirow{2}{*}{74,600} & Aug-20 & 5 day & 62,000 & Aug-20 & $-17.33 \%$ & 0 \\
\cline { 4 - 8 } & & 1 day & 74,600 & Aug-20 & 0 & 0 \\
\hline
\end{tabular}

Table 1. Quantitative forecast performance during 4th and 5th floods in 2020.

Accurate forecast of precipitation and flow. Technicians from the CROC of China Yangtze Power Co., Ltd. forecasted the extreme precipitation and floods two weeks ahead of the 4th flood qualitatively, 2 floods with both peaks of more than $60,000 \mathrm{~m}^{3} / \mathrm{s}$ a week ahead qualitatively, and the discharge and appearance times of the flood peaks 3-5 days ahead quantitatively, using the system that is responsible for precipitation and hydrology forecasting in ICJDSS (details can be seen in "Methods and materials" section). Owing to the lower accuracy of the forecast with a longer leading time ${ }^{36}$, the forecast changed from qualitative estimation to quantitative prediction with the gradual approach of the forecast target. The quantitative forecast performance is presented in Table 1.

Following the qualitative precipitation forecast of the next 7-14 days, the water level of the TGR dropped from $163.36 \mathrm{~m}$ on Jul-29 to $153.03 \mathrm{~m}$ on Aug-14 (its flood limited water level is $145 \mathrm{~m}$ ) by pre-discharging; further, $17.75 \times 10^{9} \mathrm{~m}^{3}$ of the flood control capacity was reserved, accounting for $80 \%$ of the total flood control capacity of the TGR, which ensured adequate preparation for flood control and time to adjust the power generation schedule. Following the quantitative flood forecast of the next 3-5 days, the reserved flood control capacity of upstream reservoirs (mentioned in section "Complex operating decision of super large reservoir groups") was released to hold up a portion of the flood and stagger flood peaks through real-time joint operation.

Scientific cooperation of cascade reservoir groups. In recent years, research efforts on the joint operation and coordinated management of reservoirs in the upstream Yangtze River have continued to increase, and the application of scientific cooperation of cascade reservoir groups has also been enriched.

In terms of a cooperation scheme, the flood control capacity of the reservoirs in the upper Yangtze River is reserved for cooperation with other reservoirs, and the reserved capacity is gradually released based on the flood season stages ${ }^{37,38}$ and the reservoir classifications. Specifically, (1) In the main flood season, the necessary capacity is reserved to hold the possible floods, and gradually released when the inflow shows a declining trend during the post-flood season. (2) The release order of each reservoir depends on flood encounter situations, its own flood control tasks, and its role in cooperation with the TGR for flood control of the middle and lower Yangtze River regions.

In terms of real-time cooperation, existing technology is used to predict or identify the flood type ${ }^{39}$, whereas the flood control capacity of cascade reservoirs is determined by regulating each type of flood in the entire basin during the design stage. Therefore, in the case where there is no need to prevent various flood types simultaneously, some reservoirs have surplus flood control capacity. The surplus capacity of upstream reservoirs share the flood control tasks of the downstream reservoirs, and as a result, the water levels of the downstream reservoirs can be raised to increase the benefit without increasing the flood risk of the entire basin ${ }^{40}$. In this manner, reservoirs can be compensated by the capacity of each reservoir based on the relatively accurate forecast and the joint operation pattern, so that the water levels of some reservoirs with significant benefits in the flood season can be relatively high and flexibly controlled without strictly following a single flood limit water level. For instance, with the most significant benefits in the Yangtze River, the legislative flood limit water level of TGR ranges from 145.0 to $146.5 \mathrm{~m}$. Between the $3 \mathrm{rd}$ and the 4 th flood, the water level of the TGR was reduced to $153.03 \mathrm{~m}$ by maximum discharge through turbines, rather than the flood limit water level of $145 \mathrm{~m}$ with water spillage, as the upstream reservoirs could hold up part of the flood ${ }^{41,42}$. In Fig. 4 , it can be observed from the difference between the naturalized and measured flows at the Xiangjiaba Station that the Xiangjiaba reservoir and its upstream reservoirs play an important role in flood storage and flood peak staggering; at the Gaochang and Beibei Stations, the reservoirs in the Min and Jialing Rivers also hold up part of the flood, so that the flood peaks of the Gaochang and Beibei Stations with recurrence intervals of $40-50$ years $\left(40,600 \mathrm{~m}^{3} / \mathrm{s}\right)$ and $10-15$ years $\left(38,400 \mathrm{~m}^{3} / \mathrm{s}\right)$, respectively were reduced to $10-15$ years $\left(37,500 \mathrm{~m}^{3} / \mathrm{s}\right)$ and 10 years $\left(37,400 \mathrm{~m}^{3} / \mathrm{s}\right)$, respectively.

Regulations for multi-department coordination. The Yangtze River reservoirs can be flexibly used to realize the potential benefits safely by joint operation, which is inseparable from the state macro-coordination (state FCDRH) and the cooperation of the local governments (local FCDRH), the basin management organization (CWRC), the transport department (CWB), hydropower stations and power grid companies. As an intermediary of multiple departments, $\mathrm{CROC}$ is responsible for the technical support of generating an ensemble of potential cooperation schemes and information transport and management. During the 4th and 5th flood, the above departments held 10 consultations on matters including real-time hydro-meteorological monitoring and forecast information, real-time joint operation of reservoirs, and temporary adjustment of the hydropower generation schedule. Reservoirs discharged flexibly in real-time, rather than strictly following rigid operating schedules and regulations. 
To ensure a scientific, unified, and coordinated operation of the cascade reservoir groups in the Yangtze River Basin, a series of relevant regulations have been established in recent years. In the aspect of monitoring and management, the institutional mechanism dedicated to information sharing, benefits compensation ${ }^{43}$, and risk control $^{44,45}$ for the reservoir groups has been established. In terms of the administrative system, the coordination mechanism dedicated to multiple departments involving water resources, power, shipping, and environmental protection has been improved ${ }^{46}$ based on the existing flood control organization ${ }^{47}$. On the basis of continuous improvement of the above mechanisms and systems, the legislation of the Law of the People's Republic of China on the Protection of the Yangtze River was promoted, which was promulgated on December 26, 2020, and came into force on March 1, 2021 $1^{48}$.

\section{Call for action}

Largely drawing on the reflections reported based on the reservoir cooperation during the 2020 Yangtze River, we suggest the following action points to realize the full potential of the reservoir operation of the Yangtze River basin and other basins with large reservoir groups in the world:

1. Improve flood forecast accuracy with a long lead time. Accurate flood forecast is the premise of joint and precise operation of reservoir groups, adjustment of the power generation schedule, and multi-department cooperation.

2. Continue to study the cooperation of reservoir groups. As the number of reservoirs included in the joint operation increases constantly, new situations and challenges with new requirements will gradually become prominent. It is necessary to conduct research on the cooperation of reservoir groups and to formulate scientific counter measures.

3. Improve and implement regulations for the coordinated operation of large reservoir groups. A powerful coordination regulation has the potential to guarantee effective implementation of the scientific operation of super large reservoir groups.

\section{Methods and materials}

Decision making of reservoir cooperation in upper Yangtze River Basin includes three steps. Firstly, the preliminary ensemble of cooperation schemes is obtained by Cascaded Reservoir Operation Center (CROC) through Intelligent Changjiang Decision Support System (ICDSS), powered by China Yangtze Power Co., Ltd. Secondly, departments through rounds of consultation to determine the final cooperation scheme. Finally, ICDSS reanalysis will be used to summarize the experience after the flood.

Intelligent Changjiang decision support system. Intelligent Changjiang Decision Support System is vital for the reservoir groups to optimally achieve the comprehensive operation objectives of flood control, power generation, shipping and ecology by building a tailored technology framework. ICDSS includes four main components: a data acquisition and management system; a set of interlinked models and data-model-user interactive interface; a socioeconomic evaluation system; and crisis management plans.

Data acquisition and management system. This system is responsible for automatic collecting and managing unstructured data (e.g., hydro-meteorology data, operation data and grid load data) and semi-structured data (e.g., operation regulations and instructions). In the upper Yangtze River Basin, there are 1005 hydrological stations (of which 372 are managed by local Hydrological Bureau and 633 by CRCC), 12,129 precipitation stations (of which 730 are national stations, 11,000 are local stations and 399 are managed by CROC), and 37 national ground-based radars. The failure rate of the above stations was $1.7 \%$ in the past three years.

\section{Interlinked models and data-model-user interactive interface.}

a. Simulation of upstream reservoir operation: The operation of cascade hydropower stations in the upper Yangtze River changes the propagation characteristics of natural flow, as a result, the accuracy of hydrological forecasting is affected. Therefore, this system is responsible for mining rules of impounding and discharging for upper reservoirs that is not included in joint operation and anticipating discharge of these reservoirs.

b. Hydro-meteorological forecast and discharge routing simulation ${ }^{49-52}$ : The system is composed of the Xin'anjiang model with 377 subunits, the one-dimensional hydrodynamic model, and the error correction module. Each module of the system runs automatically but can also be supplemented by human-machine interaction functions depending on the experience of the forecasters.

c. Optimal cooperation of cascade-reservoir groups with different leading time ${ }^{53-56}$ : This system is responsible for generating the optimal ensemble of reservoir cooperation based on hydro-meteorological forecast with different leading time. The NSGA-II is used to obtain the optimal cooperation schemes and Pareto solutions of corresponding objectives. Hedging theory and marginal benefit theory are used to analyze the competition between risk and benefit. As the update of forecast information with different leading time, the ensemble of reservoir cooperation is rolling executed.

Socioeconomic evaluation system. This system is responsible for evaluation and reanalysis the cooperation process of cascade-reservoir groups. By analyzing the contribution of each reservoir in cascade-reservoir groups to flood control, power generation, shipping and ecology, the influence of man-made and natural factors in the 
comprehensive achievements is clarified, and the operation scheme will be revised and improved based the reevaluation of results.

Crisis management plans. There are 22 crisis management plans for failures of automatic control systems, equipment and power, as well as kinds of accidents and emergencies.

Received: 18 August 2021; Accepted: 2 February 2022

Published online: 18 February 2022

\section{References}

1. International Federation of Red Cross and Red Crescent Societies. World Disasters Report. (2020).

2. Someya, K. Collaborative and adaptive dam operation for flood control. J. Disaster Res. 13(4), 660-667 (2018).

3. Wheeler, K. G. et al. Exploring cooperative transboundary river management strategies for the Eastern Nile Basin. Water Resour. Res. 54, 9224-9254. https://doi.org/10.1029/2017WR022149 (2018).

4. Li, H., Liu, P., Guo, S., Cheng, L. \& Yin, J. Climatic control of upper Yangtze River flood hazard diminished by reservoir groups. Environ. Res. Lett. 15, 124013 (2020).

5. Chang, J. et al. Reservoir operations to mitigate drought effects with a hedging policy triggered by the drought prevention limiting water level. Water Resour. Res. 55, 904-922. https://doi.org/10.1029/2017WR022090 (2019).

6. Li, J., Zhong, P., Yang, M. \& Zhu, F. Dynamic and intelligent modeling methods for joint operation of a flood control system. J. Water Resour. Plan. Manag. 145, 1-12 (2019).

7. Chang, J., Meng, X., Wang, Z., Wang, X. \& Huang, Q. Optimized cascade reservoir operation considering ice flood control and power generation. J. Hydrol. 519, 1042-1051 (2014).

8. Yuan, P., Wang, P. \& Zhao, Y. Novel model for manoeuvrability of ships advancing in landslide-generated tsunamis. Adv. Civil. Eng. 2020, 1-15 (2020).

9. World Commission on Dams. Dams and Development: A New Framework for Decision-Making: The Report of the World Commission on Dams (Earthscan Publications Ltd., 2000).

10. Li, C., Zhou, J., Ouyang, S., Wang, C. \& Liu, Y. Water resources optimal allocation based on large-scale reservoirs in the upper reaches of Yangtze river. Water Resour. Manag. 29, 2171-2187. https://doi.org/10.1007/s11269-015-0934-x (2015).

11. Jia, B., Zhong, P., Wan, X., Xu, B. \& Chen, J. Decomposition-coordination model of reservoir group and flood storage basin for real-time flood control operation. Hydrol. Res. 46, 11-25. https://doi.org/10.2166/nh.2013.391 (2015).

12. Meng, X., Chang, J., Wang, X., Wang, Y. \& Wang, Z. Flood control operation coupled with risk assessment for cascade reservoirs. J. Hydrol. 572, 543-555 (2019).

13. He, Y., Xu, Q., Yang, S. \& Liao, L. Reservoir flood control operation based on chaotic particle swarm optimization algorithm. Appl. Math. Model. 38, 4480-4492 (2014).

14. Piao, S. et al. The impacts of climate change on water resources and agriculture in China. Nature 467, 43-51 (2010).

15. Immerzeel, W. W., van Beek, L. P. H. \& Bierkens, M. F. P. Climate change will affect the asian water towers. Science 328, $1382-1385$ (2010).

16. Geng, Y., Wei, Z., Zhang, H. \& Maimaituerxun, M. Analysis and prediction of the coupling coordination relationship between tourism and air environment: Yangtze river economic zone in china as example. Discret. Dyn. Nat. Soc. 2020, 1-15 (2020).

17. Xia, C., Zhang, A., Wang, H., Zhang, B. \& Zhang, Y. Bidirectional urban flows in rapidly urbanizing metropolitan areas and their macro and micro impacts on urban growth: A case study of the Yangtze River middle reaches megalopolis, China. Land Use Policy 82, 158-168 (2019).

18. Gridded Population of the World. Version 4 (GPWv4): Population density adjusted to match 2015 revision UN WPP country totals, revision 11. Cent. Int. Earth Sci. Inf. Netw. https://doi.org/10.7927/H4F47M65 (2018).

19. Zhang, S., Jing, Z., Li, W., Yi, Y. \& Zhao, Y. Study of the flood control scheduling scheme for the Three Gorges Reservoir in a catastrophic flood. Hydrol. Process. 32, 1625-1634 (2018).

20. Zhou, C. et al. Optimal operation of cascade reservoirs for flood control of multiple areas downstream: A case study in the Upper Yangtze River Basin. Water https://doi.org/10.3390/w10091250 (2018).

21. Xia, J. \& Chen, J. A new era of flood control strategies from the perspective of managing the 2020 Yangtze River flood. Sci. China Earth Sci. 64, 1-9. https://doi.org/10.1007/S11430-020-9699-8 (2020).

22. Li, Z. et al. East Asian study of tropospheric aerosols and their impact on regional clouds, precipitation, and climate (EASTAIRCPC). J. Geophys. Res. Atmos. 124, 13026-13054 (2019).

23. Zhang, Y. et al. Changes in flood regime of the upper Yangtze river. Front. Earth Sci. 9, 1-13 (2021).

24. Zhou, Z., Xie, S. \& Zhang, R. Historic Yangtze flooding of 2020 tied to extreme Indian Ocean conditions. Proc. Natl. Acad. Sci. U. S. A. 118, 1-7 (2021).

25. Wei, K. et al. Reflections on the Catastrophic 2020 Yangtze River Basin Flooding in Southern China. Innovation 1, 100038 (2020).

26. Li, J., Yu, J. L. \& Hou, Y. Flood encounter analysis of main and tributary of the upper Yangtze river based on improved set pair situation ordering method. J. Catastrophol. 35, 85-92 (2020).

27. Chu, P., Liu, P. \& Pan, H. Prospects of hydropower industry in the Yangtze River Basin: China’s green energy choice. Renew. Energy 131, 1168-1185 (2019).

28. Wu, C., Wei, Y. D., Huang, X. \& Chen, B. Economic transition, spatial development and urban land use efficiency in the Yangtze River Delta, China. Habitat Int. 63, 67-78 (2017).

29. Zhamg, G., Quan, X., Yu, B. \& Zhang, Y. Optimal daily operation model and algorithm for There Gorges cascade hydropower plants. J. Yangtze River Sci. Res. Inst. 20, 10-12 (2003).

30. Jiang, Z., Li, R., Li, A. \& Ji, C. Runoff forecast uncertainty considered load adjustment model of cascade hydropower stations and its application. Energy 158, 693-708 (2018).

31. Tufegdzic, N., Frowd, R. J. \& Stadlin, W. O. A Coordinated approach for real-time short term. IEEE Trans. Power Syst. 11, 1698-1704 (1996).

32. Tang, H., Wasowski, J. \& Juang, C. H. Geohazards in the three Gorges Reservoir Area, China: Lessons learned from decades of research. Eng. Geol. 261, 105267 (2019).

33. Wu, L. \& Wang, Z. Three Gorges reservoir water level fluctuation influents on the stability of the slope's analysis. Adv. Mater. Res. 739, 283-286 (2013).

34. Chen, Y., Hu, Z., Liu, Q. \& Chen, S. Evolutionary game analysis of tripartite cooperation strategy under mixed development environment of cascade hydropower stations. Water Resour. Manag. 34, 1951-1970 (2020).

35. Ruoting, W. Three Gorges dam sets new world record of power generation in 2020. State-owned Assets Supervision and Administration Commission of the State Council http://en.sasac.gov.cn/2021/01/05/c_6354.htm (2021).

36. Kasiviswanathan, K. S., He, J., Sudheer, K. P. \& Tay, J. Potential application of wavelet neural network ensemble to forecast streamflow for flood management. J. Hydrol. 536, 161-173 (2016). 
37. Jiang, H. et al. Hydrological characteristic-based methodology for dividing flood seasons: an empirical analysis from China. Environ. Earth Sci. 78, 1-9 (2019).

38. Liu, P. et al. Optimal design of seasonal flood limited water levels and its application for the Three Gorges Reservoir. J. Hydrol. 527, 1045-1053 (2015).

39. Ran, Q. et al. Evaluation of quantitative precipitation predictions by ECMWF, CMA, and UKMO for flood forecasting: Application to two basins in China. Nat. Hazards Rev. 19, 05018003 (2018).

40. Zhou, Y., Guo, S., Chang, F. J., Liu, P. \& Chen, A. B. Methodology that improves water utilization and hydropower generation without increasing flood risk in mega cascade reservoirs. Energy 143, 785-796 (2018).

41. Zhou, Y., Guo, S., Liu, P. \& Xu, C. Joint operation and dynamic control of flood limiting water levels for mixed cascade reservoir systems. J. Hydrol. 519, 248-257 (2014).

42. Tan, Q. et al. The dynamic control bound of flood limited water level considering capacity compensation regulation and flood spatial pattern uncertainty. Water Resour. Manag. 31, 143-158 (2017).

43. Shen, Z. et al. Deriving optimal operating rules of a multi-reservoir system considering incremental multi-agent benefit allocation. Water Resour. Manag. 32, 3629-3645 (2018).

44. Ding, W., Zhang, C., Cai, X., Li, Y. \& Zhou, H. Multiobjective hedging rules for flood water conservation. Water Resour. Res. 53, 1963-1981 (2017).

45. Ding, W. et al. An analytical framework for flood water conservation considering forecast uncertainty and acceptable risk. Water Resour. Res. 51, 4702-4726 (2015).

46. Feng, M. et al. Adapting reservoir operations to the nexus across water supply, power generation, and environment systems: An explanatory tool for policy makers. J. Hydrol. 574, 257-275 (2019).

47. Liu, D., Wang, H. W., Qi, C. \& Wang, J. ORECOS: An open and rational emergency command organization structure under extreme natural disasters based on China's national conditions. Disaster Adv. 5, 63-73 (2012).

48. China’s Yangtze River Protection Law enters force. China Global Television Network (2021) https://news.cgtn.com/news/2021-0301/China-s-Yangtze-River-Protection-Law-enters-force-YgXESiyNmo/index.html.

49. Feng, Z., Niu, W., Tang, Z., Xu, Y. \& Zhang, H. Evolutionary artificial intelligence model via cooperation search algorithm and extreme learning machine for multiple scales nonstationary hydrological time series prediction. J. Hydrol. 595, 126062 (2021).

50. Zhou, J., Zhang, H., Zhang, J. \& Zeng, X. WRF model for precipitation simulation and its application in real-time flood forecasting in the Jinshajiang River Basin. Meteorol. Atmos. Phys. 130, 635-647 (2018).

51. Jiang, Z., Wu, W., Qin, H., Hu, D. \& Zhang, H. Optimization of fuzzy membership function of runo ff forecasting error based on the optimal closeness. J. Hydrol. 570, 51-61 (2019).

52. Feng, Z. et al. Monthly runo ff time series prediction by variational mode decomposition and support vector machine based on quantum-behaved particle swarm optimization. J. Hydrol. 583, 124627 (2020).

53. He, Z., Wang, C., Wang, Y., Wei, B. \& Zhou, J. Dynamic programming with successive approximation and relaxation strategy for long-term joint power generation scheduling of large-scale hydropower station group. Energy 222, 119960 (2021).

54. He, Z., Zhou, J., Xie, M., Jia, B. \& Bao, Z. Study on guaranteed output constraints in the long term joint optimal scheduling for the hydropower station group. Energy 185, 1210-1224 (2019).

55. Liu, Y. et al. Optimization of energy storage operation chart of cascade reservoirs with multi-year regulating reservoir. Energies 12, 3814 (2019).

56. Jiang, Z., Liu, P., Ji, C., Zhang, H. \& Chen, Y. Ecological fl ow considered multi-objective storage energy operation chart optimization of large-scale mixed reservoirs. J. Hydrol. 577, 123949 (2019).

\section{Acknowledgements}

This work was supported by the National Natural Science Foundation of China (Nos. 51925902, 51909010) and the Fundamental Research Funds for the Central Universities (No. DUT20RC(3)019). All data, models, or code generated or used during the study are available from the corresponding author upon reasonable request.

\section{Author contributions}

All authors contributed extensively to the work presented in this paper. H.Z., Y.D., and L.Y. conceived of and designed the paper. Y.D. and L.Y. performed some of the analysis and prepare the manuscript. H.Z., Y.D., and C.Z. provided financial support. H.Y, Z.B., Z.T., Y.W., Y.H., S.Z., M.X., J.W., C.S., Y.R., D.Z., B.W., and Y.C. contributed to the real-time reservoir cooperation. All co-authors contributed to the editing of the manuscript and to the discussion and interpretation of the results.

\section{Competing interests}

The authors declare no competing interests.

\section{Additional information \\ Correspondence and requests for materials should be addressed to Y.D. or L.Y.}

Reprints and permissions information is available at www.nature.com/reprints.

Publisher's note Springer Nature remains neutral with regard to jurisdictional claims in published maps and institutional affiliations.

(c) (i) Open Access This article is licensed under a Creative Commons Attribution 4.0 International License, which permits use, sharing, adaptation, distribution and reproduction in any medium or format, as long as you give appropriate credit to the original author(s) and the source, provide a link to the Creative Commons licence, and indicate if changes were made. The images or other third party material in this article are included in the article's Creative Commons licence, unless indicated otherwise in a credit line to the material. If material is not included in the article's Creative Commons licence and your intended use is not permitted by statutory regulation or exceeds the permitted use, you will need to obtain permission directly from the copyright holder. To view a copy of this licence, visit http://creativecommons.org/licenses/by/4.0/.

(C) The Author(s) 2022 